\title{
Saw-sedge Cladium mariscus as a functional low-cost adsorbent for effective removal of 2,4-dichlorophenoxyacetic acid from aqueous systems
}

\author{
Przemysław Bartczak $^{1}$ - Sonia Żółtowska ${ }^{1}$ Małgorzata Norman ${ }^{1}$. \\ Lukasz Klapiszewski $^{1} \cdot$ Jakub Zdarta $^{1} \cdot$ Andrzej Komosa $^{2} \cdot$ Ignacy Kitowski $^{3}$ • \\ Filip Ciesielczyk $^{1} \cdot$ Teofil Jesionowski $^{1}$
}

Received: 28 September 2015/Revised: 19 October 2015/Accepted: 22 October 2015/Published online: 20 November 2015 (C) The Author(s) 2015. This article is published with open access at Springerlink.com

\begin{abstract}
For the first time in the published literature, a study is described concerning the use of the saw-sedge Cladium mariscus (C. mariscus) for adsorption of 2,4dichlorophenoxyacetic acid (2,4-D) from aqueous systems. Among the experiments carried out, the elemental composition of $C$. mariscus was determined $(\mathrm{C}=48.0 \%$, $\mathrm{H}=7.1 \%, \mathrm{~N}=0.95 \%, \mathrm{~S}=0.4 \%$ ), FTIR spectroscopic analysis was performed to confirm the chemical structure of the adsorbent, and porous structure parameters were measured: BET surface area $\left(A_{B E T}=0.6 \mathrm{~m}^{2} / \mathrm{g}\right)$, total pore volume $\left(V_{p}=0.001 \mathrm{~cm}^{3} / \mathrm{g}\right)$ and average pore size $\left(S_{p}=6.6 \mathrm{~nm}\right)$. It was shown that the effectiveness of removal of 2,4-D from aqueous systems using $C$. mariscus depends on parameters of the process: contact time, system $\mathrm{pH}$, mass of sorbent, and temperature. Maximum adsorption was attained for a solution at $\mathrm{pH}=3$. Further increase in the alkalinity of the tested systems led to a reduction in the effectiveness of the process. The kinetic of adsorption of 2,4-D by C. mariscus was also determined, and thermodynamic aspects were investigated. The experimental data obtained correspond to a pseudo-second-order kinetic
\end{abstract}

Filip Ciesielczyk

filip.ciesielczyk@put.poznan.pl

Teofil Jesionowski

teofil.jesionowski@put.poznan.pl

1 Institute of Chemical Technology and Engineering, Faculty of Chemical Technology, Poznan University of Technology, Berdychowo 4, 60965 Poznan, Poland

2 Department of Radiochemistry and Colloid Chemistry, Maria Curie-Sklodowska University, M. Curie-Sklodowskiej 3, 20031 Lublin, Poland

3 The State School of Higher Education in Chełm, Pocztowa 54, 22100 Chełm, Poland model of type 1 . Additionally the negative values obtained for $\Delta H^{\circ}$ indicate that the process is exothermic, and the negative values of $\Delta G^{\circ}$ show it to be spontaneous. As the temperature of the system increases the spontaneity of adsorption is reduced, in accordance with the exothermic nature of the process.

Keywords Low-cost adsorbents - Cladium mariscus . Adsorption · 2,4-dichlorophenoxyacetic acid . Thermodynamic studies

\section{Introduction}

In the last decade there has been considerable development in agriculture caused not only by the mechanization of manufacturing, but also by progress in the production of plant protection products (pesticides). However, pesticides cannot be equated only with agrotechnology. Plant protection products are commonly used in forestry, orcharding and even in backyard plots and gardens. In spite of the many advantages of using pesticides, it should be borne in mind that these substances are the main source of water pollution. This is due to the fact that these compounds easily penetrate the soil and pollute surface and ground water. Additionally, in most cases, they are toxic, carcinogenic and mutagenic (Aktar et al. 2009; Salman 2014; Shabeer et al. 2014; Sultana et al. 2014; Yang et al. 2014).

2,4-Dichlorophenoxyacetic acid (2,4-D) is the most popular pesticide or main component of plant protection products used throughout the world. It is a herbicide whose activity is based on the stimulation of cells to uncontrolled growth, which leads to the death of the plant in the final stage. It is commonly used in the cultivation of maize, soya, hazelnuts, sugar cane and spring wheat. 2,4-D is 
extremely toxic to organisms other than its targets. It is especially dangerous to aquatic organisms. It has a negative influence on the proper functioning of the human body; it is carcinogenic, mutagenic, and causes damage to the liver, kidneys and central nervous system. In addition, 2,4-D is poorly biodegradable, which means that it is stable in ambient conditions (Bradberry et al. 2004; Derylo-Marczewska et al. 2010; Garabant and Philbert 2002; Kaminski et al. 2014, Tomlin 2009).

The elimination of pesticides from water systems is a fundamental issue addressed by researchers around the world. Several techniques have been developed for the removal of organic pollution from water. The most frequently used methods, which include physical, chemical and biological processes, are photo-oxidation, chemical coagulation, sedimentation, filtration, disinfection, ion exchange, flotation, adsorption and electrochemical methods (Aksu and Kabasakal 2004; Bartczak et al. 2015; Goscianska et al. 2013, 2014; Mohammad et al. 2014; Nam et al. 2014; Ova and Ovez 2013; Pirsaheb et al. 2014; Souzaa et al. 2015; Zhang et al. 2014). In recent years, the adsorption process has become increasingly popular, as an effective method of removing pesticides from water systems. It is an attractive method because of its simplicity and low cost. In the last decade, low-cost natural-origin adsorbents have aroused increasing interest among researchers throughout the world. The use of this group of adsorbents decreases process costs, making this method an attractive alternative to conventional techniques of water and sewage purification. Saw-sedge Cladium mariscus (C. mariscus) can be included in the group of natural-origin materials (Theocharopoulos et al. 2006). It is a perennial monocot, belonging to the sedge family. It occurs on all continents except Antarctica. C. mariscus is an interesting material that has not previously been used and studied as an adsorbent of inorganic and organic impurities.

The phenomenon of 2,4-D adsorption is the subject of many ongoing research projects around the world. Numerous sorption materials are used for this process, including activated carbon, materials obtained from coconut shells, chitin and chitosan, and silica gel modified with cationic surfactants (Harmoudi et al. 2014; Koner et al. 2013; Njoku et al. 2014). Series of tests are performed to determine the character of the adsorbent in question, the kinetics of the process and the adsorption isotherms.

The adsorption process is a universal method for removing pesticides from aqueous systems (Ali et al. 2012). A multiplicity of studies show that this process is an alternative to conventional water treatment methods. The possibility of re-use of sorbents makes it competitive with respect to other methods of water purification.

In the present work, for the first time, an investigation was made of the use of Cladium mariscus as a potential adsorbent of 2,4-D. There is so far no information available in the literature concerning the use of this material, which confirms the novel nature of the present research. In the study, basic parameters of the adsorption process were determined. The adsorption kinetic was investigated using pseudo-first-order (Lagergren 1898) and pseudo-secondorder (Ho 1999) models, and adsorption isotherms were determined using the Freundlich (1906) and Langmuir (1918) models. Thermodynamic aspects of the process were also investigated. An essential objective of the research was to determine the presumed mechanism of the process.

\section{Materials and methods}

\subsection{Reagents and chemicals}

The following reagents were used in the experiments: 2,4dichlorophenoxyacetic acid (Merck KGaA, Germany) as the adsorbate, and hydrochloric acid (Chempur, Poland) and sodium hydroxide (Chempur, Poland) for $\mathrm{pH}$ adjustment.

\subsection{Preparation of adsorbent}

Cladium mariscus was collected in the vicinity of Chełm, Lublin region, Poland. The leaves of the plant were washed with distilled water and dried for $24 \mathrm{~h}$ at $105{ }^{\circ} \mathrm{C}$. The next step involved reducing the adsorbent to an appropriate fineness. The plant material prepared in this way was then subjected to physicochemical analysis and used in adsorption tests.

\subsection{Characterization of the biosorbent}

The most important physicochemical and structural properties of the material were determined, with regard to its application as an effective adsorbent (elemental analysis, FTIR spectroscopy for identification of functional groups, and porous structure analysis). The elemental composition of C. mariscus was established using a Vario El Cube instrument (Elementar Analysensysteme $\mathrm{GmbH}$, Germany). To identify the functional groups present in the structure of C. mariscus, Fourier transform infrared spectroscopy was applied. The measurements were performed using a VERTEX 70 spectrophotometer (Bruker, Germany). Substances were analyzed in a form of tablets prepared by mixing ca. $250 \mathrm{mg}$ of anhydrous $\mathrm{KBr}$ with $1.5 \mathrm{mg}$ of the sample. Spectra were produced over a wavenumber range of $4000-400 \mathrm{~cm}^{-1}$, with a resolution of $0.5 \mathrm{~cm}^{-1}$. To make a full physicochemical characterization of C. mariscus it was necessary to determine its porous 
structure parameters (surface area and pore size distribution). These parameters were measured by means of lowtemperature $\mathrm{N}_{2}$ sorption using an ASAP 2020 instrument (Micromeritics Instrument Co., USA). Surface area was determined to an accuracy of $\pm 0.1 \mathrm{~m}^{2} / \mathrm{g}$, pore volume to $\pm 0.01 \mathrm{~cm}^{3} / \mathrm{g}$, and pore size to $0.01 \mathrm{~nm}$.

\subsection{Batch adsorption studies}

The experimental studies first involved determination of the sorption capacity of $C$. mariscus with respect to 2,4-D and investigation of how selected process parameters influence the effectiveness of adsorption. The values of the variable process parameters are given in Table 1 .

To determine the effect of contact time between adsorbate and adsorbent, the appropriate quantity of sorbent was weighed out (see Table 1) and was placed in conical flasks with $100 \mathrm{~mL}$ of model solution of 2,4-D at a specified concentration. The system was mixed using a KS 260 Basic shaker (IKA, Germany) for a specified time (1-120 min). The mixture was then filtered at reduced pressure. The effectiveness of the process was determined using a UVVis SPEKOL 1200 spectrophotometer (Analytik Jena AG, Germany) at wavelength $230 \mathrm{~nm}$. The adsorbent was dried at $105{ }^{\circ} \mathrm{C}$ in a UE 500 drier (Memmert, Germany) and was subjected to further analysis.

To determine the influence of $\mathrm{pH}$ on the effectiveness of adsorption of 2,4-D, an appropriate quantity of sodium hydroxide or $\mathrm{HCl}$ was added to the model solution. The $\mathrm{pH}$ values were controlled with the use of an EL $20 \mathrm{pH}$ meter (Mettler Toledo, Switzerland). After the desired $\mathrm{pH}$ was attained, the appropriate quantity of Cladium mariscus was added to the system.

The final analyzed process parameter was temperature, which was controlled using a KS 4000i incubator (IKA, Germany).

\subsection{Kinetic and isothermal studies}

An important element of the study was the determination of the kinetic of adsorption of 2,4-D by C. mariscus based on models of pseudo-first-order (Lagergren 1898) and pseudosecond-order (Ho 1999) type. To determine the kinetics of the adsorption process it was necessary to perform calculations concerning the quantity of 2,4-D adsorbed in a given time $\left(q_{t}\right)$. This was calculated from the following Eq. (1):

$q_{t}=\frac{\left(C_{0}-C_{t}\right) \cdot V}{m}$

where $C_{O}$ and $C_{t}$ denote the concentration of 2,4-D before and after the adsorption process $(\mathrm{mg} / \mathrm{L}), V$ is the volume of model solution (L), and $m$ is the mass of adsorbent used (g).

For the determination of adsorption isotherms using Freundlich (1906) and Langmuir models (1918), it was necessary to find the equilibrium concentration $\left(q_{e}\right)$ of adsorbed 2,4-D acid on $C$. mariscus. This was calculated using the following formula (2):

$q_{e}=\frac{\left(C_{0}-C_{e}\right) \cdot V}{m}$

where $C_{0}$ and $C_{e}$ denote the concentration of 2,4-D before the adsorption process and in equilibrium $(\mathrm{mg} / \mathrm{L}), V$ is the volume of model solution (L), and $m$ is the mass of adsorbent used $(\mathrm{g})$.

\section{Results and discussion}

\subsection{Physicochemical characteristics of Cladium mariscus}

Cladium mariscus, as a potential sorbent of 2,4dichlorophenoxyacetic acid, was subjected to thorough physicochemical analysis. Elemental analysis was applied to determine the content of $\mathrm{C}, \mathrm{H}, \mathrm{N}$ and $\mathrm{S}$ in the plant structure (Table 2).

It also contains oxygen, which was not detected directly by this method. C. mariscus mainly consists of carbon and hydrogen (48.0 and $7.1 \%$ respectively), similarly to other sorbents of plant origin (tea grounds, the seaweed Ascophyllum nodosum, sawdust, and the grass Phragmites australis-Akunwa et al. 2014; Foroughi-Dahr et al. 2015). The presence of nitrogen $(0.9 \%)$ can be explained by the occurrence of amide and amine groups in the material structure, which was also confirmed by further analysis of the FTIR spectra.

Table 1 Process conditions for the removal of 2,4-D acid by Cladium mariscus

\begin{tabular}{lll}
\hline Optimized parameter & Values analyzed & Adsorption process conditions \\
\hline Time $(\min )$ & $1,3,5,10,15,30,60,120$ & $\mathrm{pH} 4.5 ;$ temperature $25{ }^{\circ} \mathrm{C} ;$ mass of adsorbent $5 \mathrm{~g} / \mathrm{L} ; \mathrm{C}_{0}=20,30,50 \mathrm{and} 100 \mathrm{mg} / \mathrm{L}$ \\
$\mathrm{pH}$ & $1 ; 2 ; 3 ; 4.5 ; 7 ; 9$ & Time: $60 \mathrm{~min} ;$ temperature $25{ }^{\circ} \mathrm{C} ;$ mass adsorbent $5 \mathrm{~g} / \mathrm{L} ; \mathrm{C}_{0}=50 \mathrm{mg} / \mathrm{L}$ \\
Mass of the adsorbent $(\mathrm{g} / \mathrm{L})$ & $1,2,5,10,15$ & Time: $60 \mathrm{~min}$; temperature $25{ }^{\circ} \mathrm{C} ; \mathrm{pH}=4.5 ; \mathrm{C}_{0}=50 \mathrm{mg} / \mathrm{L}$ \\
Temperature $\left({ }^{\circ} \mathrm{C}\right)$ & $25,30,35$ & Time: 60 min; mass of adsorbent $5 \mathrm{~g} / \mathrm{L} ; \mathrm{C}_{0}=50 \mathrm{mg} / \mathrm{L} ; \mathrm{pH}=4.5$ \\
\hline
\end{tabular}


Table 2 Elemental composition and parameters of porous structure of Cladium mariscus

\begin{tabular}{llll}
\hline \multicolumn{2}{l}{ Elemental content $(\%)$} & & \\
\hline C & $\mathrm{H}$ & $\mathrm{N}$ & $\mathrm{S}$ \\
\hline 48.0 & 7.1 & 0.9 & 0.4 \\
\hline
\end{tabular}

Parameters of porous structure

\begin{tabular}{lll}
\hline $\begin{array}{l}\text { Surface area } A_{B E T} \\
\left(\mathrm{~m}^{2} / \mathrm{g}\right)\end{array}$ & $\begin{array}{l}\text { Pore volume } V_{p}\left(\mathrm{~cm}^{3} /\right. \\
\mathrm{g})\end{array}$ & $\begin{array}{l}\text { Pore diameter } S_{p} \\
(\mathrm{~nm})\end{array}$ \\
\hline 0.6 & 0.001 & 6.6 \\
\hline
\end{tabular}

When investigating the use of adsorbents of natural origin, it is extremely important to determine their porous structure parameters. The results showed this plant to have a very low surface area of $0.6 \mathrm{~m}^{2} / \mathrm{g}$ and a pore volume of $0.001 \mathrm{~cm}^{3} / \mathrm{g}$. However, these parameters do not exclude the application of $C$. mariscus in adsorption processes. In this case, the sorptive capacity of the material depends on the presence of specific functional groups on its surface.

To identify those groups in the structure of C. mariscus, FTIR spectra were obtained and analyzed (Fig. 1). The presence of hydroxyl groups was confirmed by the occurrence of bands in the range $3550-3000 \mathrm{~cm}^{-1}$, derived from stretching vibrations of $\mathrm{O}-\mathrm{H}$ bonds. This band substantially masks the band derived from stretching vibrations of $\mathrm{N}-\mathrm{H}$ bonds $\left(3300-3250 \mathrm{~cm}^{-1}\right)$ from amine and amide groups. The presence of aliphatic groups was indicated by the bands derived from stretching vibrations of $\mathrm{C}-\mathrm{H}$ bonds in the range $3000-2800 \mathrm{~cm}^{-1}$. There is also a noticeable band derived from stretching vibrations of $\mathrm{C}-\mathrm{O}$ bonds in the range $1750-1700 \mathrm{~cm}^{-1}$, which indicates the presence of carbonyl groups. The occurrence of ether groups was confirmed by the bands in the range $1100-1000 \mathrm{~cm}^{-1}$,

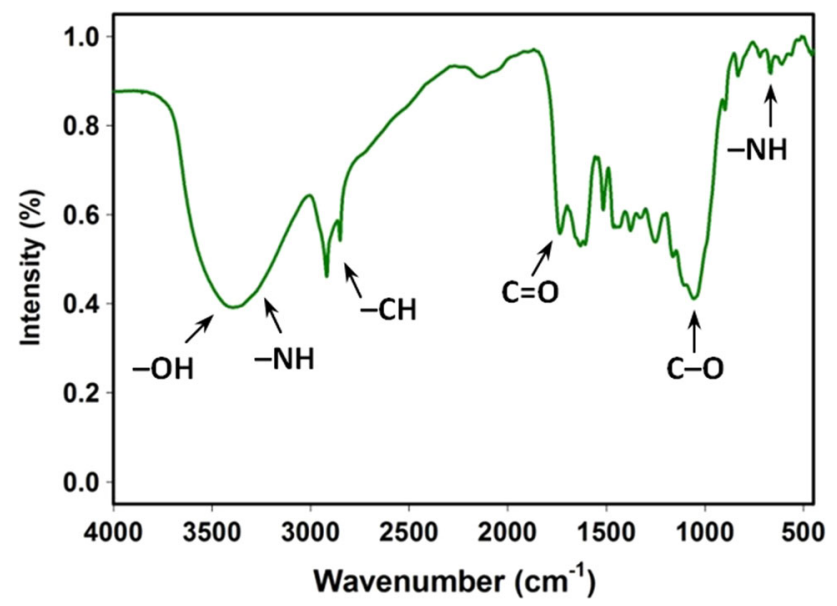

Fig. 1 FTIR spectrum of Cladium mariscus derived from stretching vibrations of $\mathrm{C}-\mathrm{O}-\mathrm{C}$ and $\mathrm{C}-\mathrm{O}$ groups. In the range $720-630 \mathrm{~cm}^{-1}$ there are bands derived from bending vibrations of $\mathrm{N}-\mathrm{H}$ bonds (amine groups). In this wavenumber range there are also vibrations proving the presence of $\mathrm{C}-\mathrm{C}$ bonds, which are typical for aromatic rings.

Analysis of the FTIR spectra confirms the presence of numerous groups in the material structure and due to these groups the adsorbent can exhibit a remarkable capacity to adsorb impurities from aqueous systems.

The physicochemical analysis of the plant confirms the considerable possibilities of application of the material as an effective adsorbent of different kind of impurities.

\subsection{Effect of adsorption time and kinetic study}

In the first stage of the study it was investigated how the contact time between adsorbate and adsorbent influences the effectiveness of removal of 2,4-D from aqueous systems. This was done for four concentrations of 2,4-D: 20, 30, 50 and $100 \mathrm{mg} / \mathrm{L}$ (Fig. 2).

The results indicate that in the initial stage adsorption proceeded extremely rapidly. In the first $5 \mathrm{~min}$ the effectiveness of adsorption for each concentration was greater than $50 \%$. Adsorption equilibrium was reached after $30 \mathrm{~min}$ for an initial 2,4-D concentration of 20 or $30 \mathrm{mg} / \mathrm{L}$, and after $60 \mathrm{~min}$ for $50 \mathrm{mg} / \mathrm{L}$ and for the highest analyzed concentration, $100 \mathrm{mg} / \mathrm{L}$. The maximum adsorption yields were respectively 99.9, 99.0, 99.0 and $95.9 \%$ for model solutions with 2,4-D concentrations of $20,30,50$ and $100 \mathrm{mg} / \mathrm{L}$. After the elapse of the optimum process time, no significant changes were recorded for any of the analyzed concentrations.

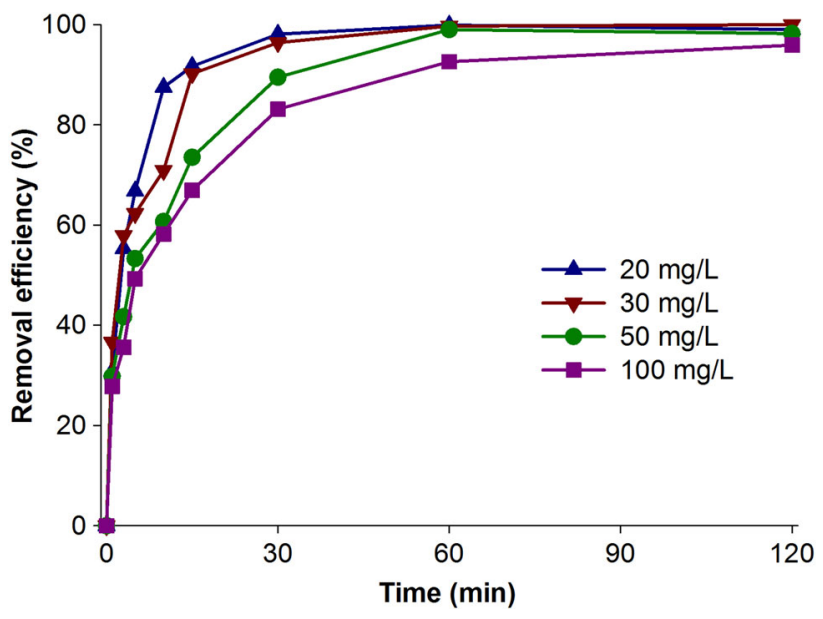

Fig. 2 Effect of contact time on 2,4-D removal by Cladium mariscus (2,4-D concentration $20-100 \mathrm{mg} / \mathrm{L}$, adsorbent dose $0.5 \mathrm{~g}, \mathrm{pH} 4.5$, temperature $25{ }^{\circ} \mathrm{C}$ ) 
It should also be noted that the effectiveness of adsorption is also significantly influenced by the initial concentration of 2,4-D. The results indicate that as the 2,4$\mathrm{D}$ concentration increases, the effectiveness of its removal decreases slightly, leading to an increase in the time required to attain an equilibrium state. This is because an increased quantity of 2,4-D anions diffuse to the sorbent surface through the boundary layer, increasing the time taken for adsorption equilibrium to be reached. The reduction in the effectiveness of adsorption with increased concentration of the solution of adsorbate results from the saturation of active sites capable of adsorbing 2,4-D.

Compared with other sorbents, the use of $C$. mariscus led to rapid attainment of adsorption equilibrium. When activated carbon was used, as described by Hammed et al. (2009), adsorption equilibrium was reached after $450 \mathrm{~min}$. Aksu and Kabasakal (2005) carried out adsorption of 2,4-D on activated carbon and found equilibrium to be attained after 7 days. The properties of $C$. mariscus mean that it could be successfully used in industry, since the fast reaction time would enable a reduction in the volume of the tanks used as reactors.

A determination was also made of the kinetic of the adsorption of 2,4-dichlorophenoxyacetic acid from model solutions with the lowest and highest concentrations (20 and $100 \mathrm{mg} / \mathrm{L})$. The kinetic of the process of adsorption of 2,4-D by $C$. mariscus was determined using a pseudo-firstorder model (of Lagergren type 1898) and a pseudo-second-order model (as described by Ho 1999).

The aforementioned models present the correlations between changes in the concentration of adsorbate as a function of the time for which the adsorption process is continued until equilibrium is reached. Linear and graphical forms of the models are given in Table 3.

Here $q_{e}$ and $q_{t}(\mathrm{mg} / \mathrm{g})$ denote the quantities of 2,4-D adsorbed at equilibrium and at time $t(\mathrm{~min}), k_{l}(1 / \mathrm{min})$ is the rate constant for the adsorption process for the pseudofirst-order model, and $k_{2}(\mathrm{~g} /(\mathrm{mg} \min ))$ is the rate constant for the process for the pseudo-second-order model.

The kinetic parameters (Table 4) describing the pseudofirst-order as well as pseudo-second-order model type 1, 2,
3 and 4 were calculated from plots presented in Fig. 3 and 4 , respectively.

Analysis of the obtained kinetic parameters (Table 4) shows that the experimental data correspond directly to the pseudo-second-order kinetic model. This is confirmed by the high correlation coefficient $\left(r^{2}=0.998-0.999\right)$ obtained for the pseudo-second-order model type 1 . It should also be noted that the quantities of adsorbed 2,4-D $\left(q_{\text {e.cal }}\right)$ computed using that model correspond closely to the experimental values $\left(q_{\text {e.exp }}\right)$. The adsorption rate coefficient $\left(k_{2}\right)$ was found to decrease with increasing concentration of 2,4-D in the model solution.

Other researchers have determined the kinetics of adsorption of 2,4-D on selected adsorbents (Aksu and Kabasakal 2005; Chaparadza and Hossenlopp 2011; Gupta et al. 2006; Hameed et al. 2009; Nethaji and Sivasamy 2014; Salman and Al-Saad 2012). The kinetic parameters obtained by them are listed in Table 5. Determination of the adsorption kinetic is important for controlling the effectiveness of the removal of 2,4-D from aqueous systems. Adsorption of 2,4-D using various different types of material is described in most cases by means of a pseudosecond-order model.

The coefficients of correlation $\left(r^{2}\right)$ obtained using the pseudo-second-order kinetic model of type 2, 3 and 4 (0.754-0.980) are significant lower than those obtained using the type 1 model. Additionally, the $q_{e, \text { cal }}$ computed from the pseudo-second-order kinetic models of type 2, 3 and 4 do not correspond with the $q_{e \text { exp }}$ the same as in the case of 1 st sub-type.

\subsection{Effect of $\mathrm{pH}$}

Another important part of the study involved determining how the $\mathrm{pH}$ of the system influences the effectiveness of adsorption of 2,4-D from model aqueous solutions (Fig. 5).

The results show that as the $\mathrm{pH}$ of the solution increases (in the $\mathrm{pH}$ range 1-3) the effectiveness of adsorption increases, reaching a maximum at $\mathrm{pH}=3$ (yield 99.1\%). A further increase in the alkalinity of the solution causes a reduction in effectiveness, which at the highest tested $\mathrm{pH}$
Table 3 Linear and graphical forms of pseudo-first and pseudo-second order kinetic models

\begin{tabular}{lll}
\hline Type of kinetic model & Linear form & Plot \\
\hline Pseudo-first order & $\log \left(q_{e}-q_{t}\right)=\log q_{e}-\frac{k_{1}}{2.303} t$ & $\log \left(q_{e}-q_{t}\right)$ vs. $t$ \\
Pseudo-second order & $\frac{t}{q_{t}}=\frac{1}{k_{2} q_{e}^{2}}+\frac{1}{q_{e}} t$ & \\
Type 1 & $\frac{1}{q_{t}}=\left(\frac{1}{k_{2} q_{e}^{2}}\right) \frac{1}{t}+\frac{1}{q_{e}}$ & $\frac{t}{q_{t}}$ vs. $t$ \\
Type 2 $\frac{1}{t}$ \\
Type 3 & $\frac{1}{t}=\frac{k_{2} q_{e}^{2}}{q_{t}}-\frac{k_{2} q_{e}^{2}}{q_{e}}$ & $\frac{t}{t}$ vs. $\frac{1}{q_{t}}$ \\
Type 4 & $\frac{q_{t}}{t}=k_{2} q_{e}^{2}-\frac{k_{2} q_{e}^{2}}{q_{e}}$ & $\frac{q_{t}}{t}$ vs. $q_{t}$ \\
\hline
\end{tabular}


Table 4 Pseudo-first-order and pseudo-second-order kinetic parameters concerning adsorption of 2,4-D onto Cladium mariscus

\begin{tabular}{|c|c|c|c|c|c|c|c|}
\hline \multirow[t]{2}{*}{ Type of model kinetic } & & \multicolumn{2}{|c|}{ Parameter } & \multicolumn{4}{|c|}{ Concentration of 2,4-D (mg/L) } \\
\hline & & Symbol & Unit & 20 & 30 & 50 & 100 \\
\hline \multirow[t]{4}{*}{ Pseudo-first order } & & $q_{\text {e.exp }}$ & $\mathrm{mg} / \mathrm{g}$ & 4.00 & 5.98 & 9.90 & 19.18 \\
\hline & & $q_{\text {e.cal }}$ & $\mathrm{mg} / \mathrm{g}$ & 2.12 & 3.67 & 6.82 & 12.89 \\
\hline & & $k_{l}$ & $1 / \min$ & 0.12 & 0.10 & 0.07 & 0.05 \\
\hline & & $r^{2}$ & - & 0.980 & 0.965 & 0.987 & 0.995 \\
\hline \multirow[t]{12}{*}{ Pseudo-second order } & Type 1 & $q_{e . c a l}$ & $\mathrm{mg} / \mathrm{g}$ & 4.03 & 6.15 & 10.24 & 20.03 \\
\hline & & $k_{2}$ & $\mathrm{~g} /(\mathrm{mg} \min )$ & 0.17 & 0.06 & 0.05 & 0.02 \\
\hline & & $r^{2}$ & - & 0.999 & 0.999 & 0.999 & 0.998 \\
\hline & Type 2 & $q_{e, c a l}$ & $\mathrm{mg} / \mathrm{g}$ & 3.93 & 5.48 & 8.43 & 15.32 \\
\hline & & $k_{2}$ & $\mathrm{~g} /(\mathrm{mg} \min )$ & 0.17 & 0.13 & 0.06 & 0.03 \\
\hline & & $r^{2}$ & - & 0.980 & 0.925 & 0.931 & 0.884 \\
\hline & Type 3 & $q_{e, c a l}$ & $\mathrm{mg} / \mathrm{g}$ & 3.95 & 5.62 & 8.71 & 16.23 \\
\hline & & $k_{2}$ & $\mathrm{~g} /(\mathrm{mg} \min )$ & 0.17 & 0.12 & 0.05 & 0.03 \\
\hline & & $r^{2}$ & - & 0.980 & 0.925 & 0.931 & 0.884 \\
\hline & Type 4 & $q_{e, c a l}$ & $\mathrm{mg} / \mathrm{g}$ & 4.04 & 5.92 & 9.56 & 18.14 \\
\hline & & $k_{2}$ & $\mathrm{~g} /(\mathrm{mg} \min )$ & 0.15 & 0.09 & 0.04 & 0.02 \\
\hline & & $r^{2}$ & - & 0.956 & 0.832 & 0.815 & 0.754 \\
\hline
\end{tabular}

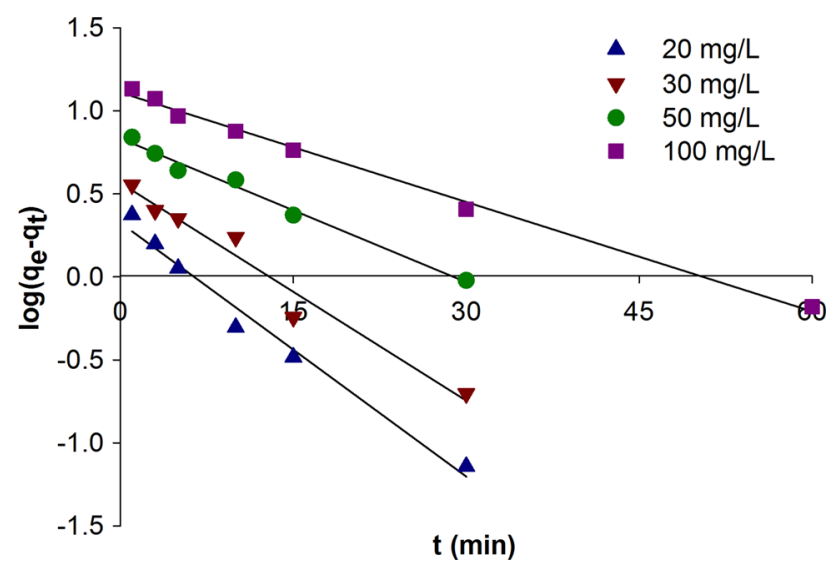

Fig. 3 Linear forms of pseudo-first-order kinetic model related with adsorption of 2,4-D by Cladium mariscus

value ( $\mathrm{pH}=9$ ) was found to be $55.3 \%$. The $\mathrm{pH}$ value of the system plays a key role in defining the mechanism of adsorption of 2,4-D on the surface of $C$. mariscus.

Figure 6 shows a proposed mechanism for the adsorption of 2,4-D on the complex surface of $C$. mariscus. The presence of surface functional groups (carbonyl, amide, ether) capable of releasing a free electron pair to form a bond suggests adsorption by way of a chemical reaction. However, the protonating ability of surface functional groups (hydroxyl, amine, amide) would indicate adsorption through intermolecular interactions (including cationdipole interactions and hydrogen bonds).

Above the $\mathrm{pH}$ corresponding to the pKa value (2.73), 2,4-D occurs in the form of an anion. The maximum effectiveness of adsorption was obtained for $\mathrm{pH}=3$, which implies that the mechanism is based, to by far the greatest degree, on electrostatic interaction between the anion of 2,4-D and the surface functional groups (having a positive charge - Fig. 6). A much lesser role in the overall adsorption process is played by chemisorption and ion exchange.

\subsection{Effect of adsorbent dose}

Another important parameter that was analyzed is the mass of sorbent (Fig. 7). An increase in effectiveness of 2,4-D acid removal together with increasing mass of adsorbent was observed. This is because an increase in the mass of sorbent causes an increase in the adsorptive (contact) surface and an increase in the quantity of surface functional groups capable for removing 2,4-D, which leads to an increase in the effectiveness of the adsorption process. It was confirmed that adsorbent dose of $10 \mathrm{~g} / \mathrm{L}$ and $60 \mathrm{~min}$ time is enough to completely clean the solution which contains $50 \mathrm{mg} / \mathrm{L}$ of 2,4-D.

\subsection{Effect of temperature and thermodynamic studies}

The last parameter analyzed was the temperature of the system (Fig. 8a). It was found that as temperature increased, the effectiveness of removal of 2,4-D slightly decreased. This suggests that the adsorption process may be of an exothermic nature. 

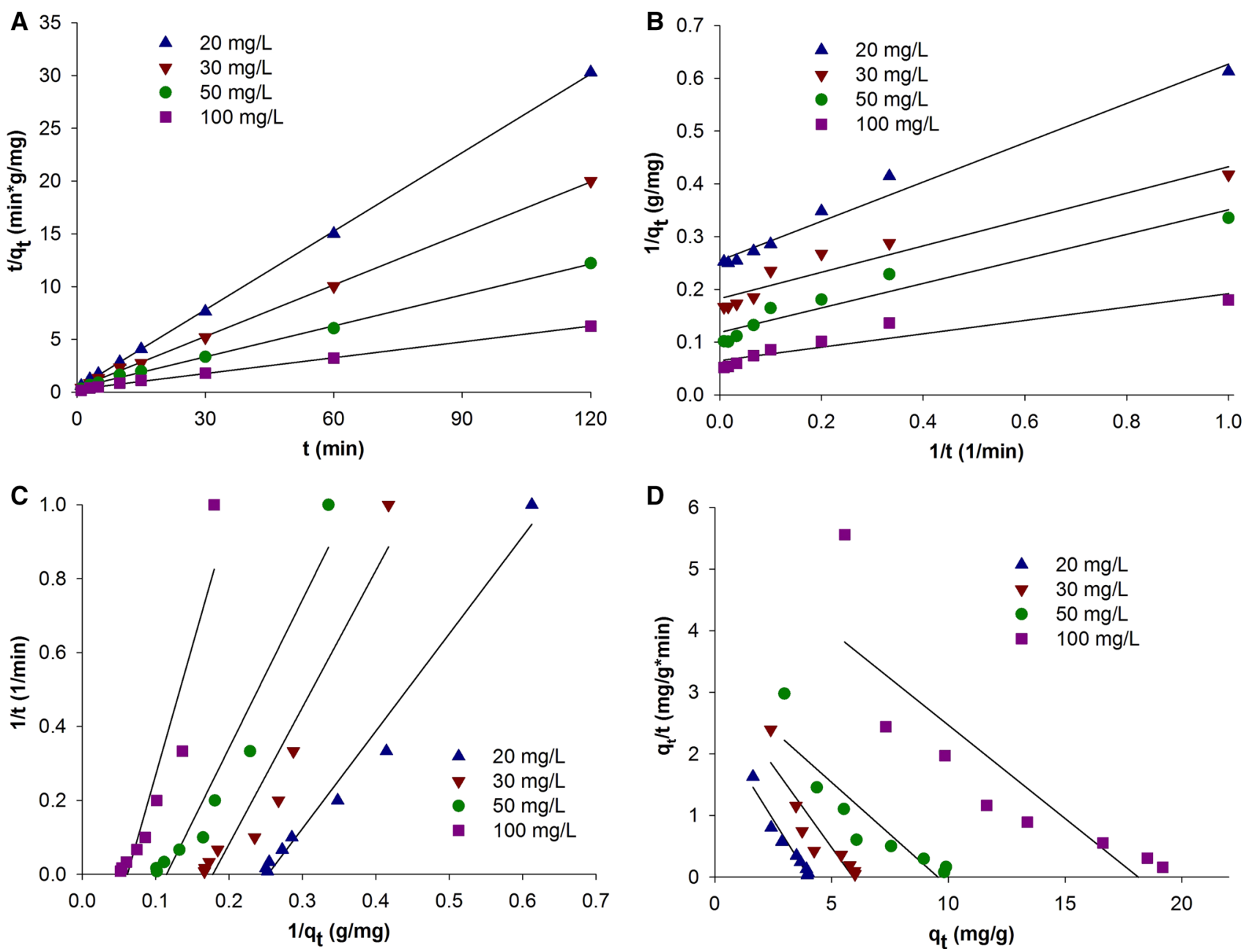

Fig. 4 Type 1 (a), 2 (b), 3 (c) and 4 (d) of pseudo-second-order kinetic model obtained using a linear method

Table 5 The kinetic parameters describe the adsorption kinetic models of 2,4-D in the selected adsorbents

\begin{tabular}{|c|c|c|c|c|}
\hline Adsorbent & $\begin{array}{l}\text { Type of kinetic } \\
\text { model }\end{array}$ & $r^{2}$ & $\begin{array}{l}k_{1} / k_{2}(1 / \mathrm{min})(\mathrm{g} / \\
(\mathrm{mg} \cdot \min ))\end{array}$ & Reference \\
\hline Activated carbon derived from date stones & Pseudo-first order & 0.992 & 0.915 & Hameed et al. (2009) \\
\hline Calcined Zn-Al.-Zr layered double hydroxide & $\begin{array}{l}\text { Pseudo-second } \\
\text { order }\end{array}$ & 0.990 & 0.004 & $\begin{array}{l}\text { Chaparadza and Hossenlopp } \\
\text { (2011) }\end{array}$ \\
\hline Fertilizer and steel industry wastes & $\begin{array}{l}\text { Pseudo-second } \\
\text { order }\end{array}$ & 0.992 & 0.002 & Gupta et al. (2006) \\
\hline $\begin{array}{l}\text { Magnetite activated carbon derived from waste } \\
\text { biomass }\end{array}$ & $\begin{array}{l}\text { Pseudo-second } \\
\text { order }\end{array}$ & 0.999 & 0.012 & Nethaji and Sivasamy (2014) \\
\hline Seeds activated carbon & $\begin{array}{l}\text { Pseudo-second } \\
\text { order }\end{array}$ & 0.998 & 0.041 & Salman and Al-Saad (2012) \\
\hline
\end{tabular}

This property of the process may result from the fact that interactions of anions of 2,4-D with functional groups on the plant surface are stronger than the interactions of the initially adsorbed water on the surface of the sorbent. This indicates strong electrostatic interactions between 2,4-D anions and the sorbent surface.

Other researchers studying the adsorption of 2,4-D have obtained similar results. Aksu and Kabasakal (2005), who 


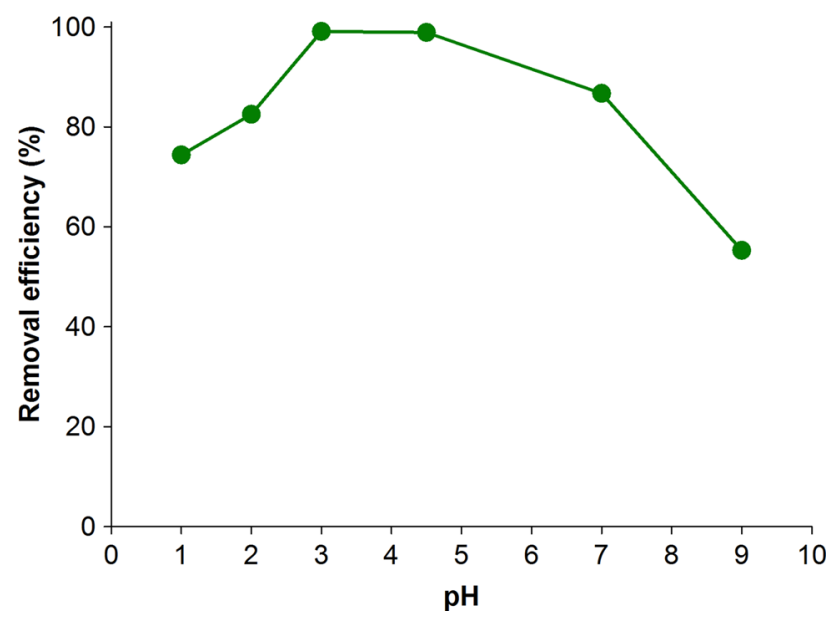

Fig. 5 Effect of $\mathrm{pH}$ on 2,4-D removal by Cladium mariscus (2,4-D concentration $50 \mathrm{mg} / \mathrm{L}$, adsorbent dose $0.5 \mathrm{~g}$, time $60 \mathrm{~min}$, temperature $25^{\circ} \mathrm{C}$ )

investigated the adsorption of 2,4-D on granulated activated carbon, showed the process to be exothermic. Similar results were obtained by Gupta et al. (2006), who carried out adsorption of 2,4-D using a suspension of activated carbon.

The adsorption of 2,4-D on low-cost adsorbents is not always exothermic. Koner et al. (2013) showed that adsorption on the surface of a modified waste silica gel was endothermic.

Another important part of the work was the investigation of thermodynamic aspects of the process of adsorption of 2,4-D by C. mariscus. An analysis was made for four different concentrations of model solutions $(20,30,50$ and $100 \mathrm{mg} / \mathrm{L})$ at three temperatures $\left(25,30\right.$ and $\left.35^{\circ} \mathrm{C}\right)$.

Calculations were made of the free energy $\left(\Delta G^{\circ}\right)$, enthalpy $\left(\Delta H^{\circ}\right)$ and entropy $\left(\Delta S^{\circ}\right)$ of the systems, using Eqs. (3-5):

$\Delta G^{\circ}=-R T \ln K_{c}$

$\ln K_{c}=\frac{\Delta S^{\circ}}{R}-\frac{\Delta H^{\circ}}{R T}$

$\Delta G^{\circ}=\Delta H^{\circ}-T \Delta S^{\circ}$

where $\Delta G^{\circ}(\mathrm{kJ} / \mathrm{mol})$ is the change in the free energy of the system, $\Delta H^{\circ}(\mathrm{kJ} / \mathrm{mol})$ is the change in the free enthalpy of the system, $\Delta S^{\circ}(\mathrm{kJ} / \mathrm{mol} \mathrm{K})$ is the change in the free entropy of the system, $R(8.314 \mathrm{~J} / \mathrm{mol} \mathrm{K})$ is the gas constant, $K_{c}$ is the reaction equilibrium constant, and $T(\mathrm{~K})$ is the temperature.

The changes in enthalpy and entropy were calculated based on the plot of $\ln K_{c}$ against $1 / T$ (Fig. 8b), using its slope $\left(-\frac{\Delta H^{\circ}}{R}\right)$ and $\mathrm{y}$-axis intercept $\left(\frac{\Delta S^{\circ}}{R T}\right)$. The results are given in Table 6.

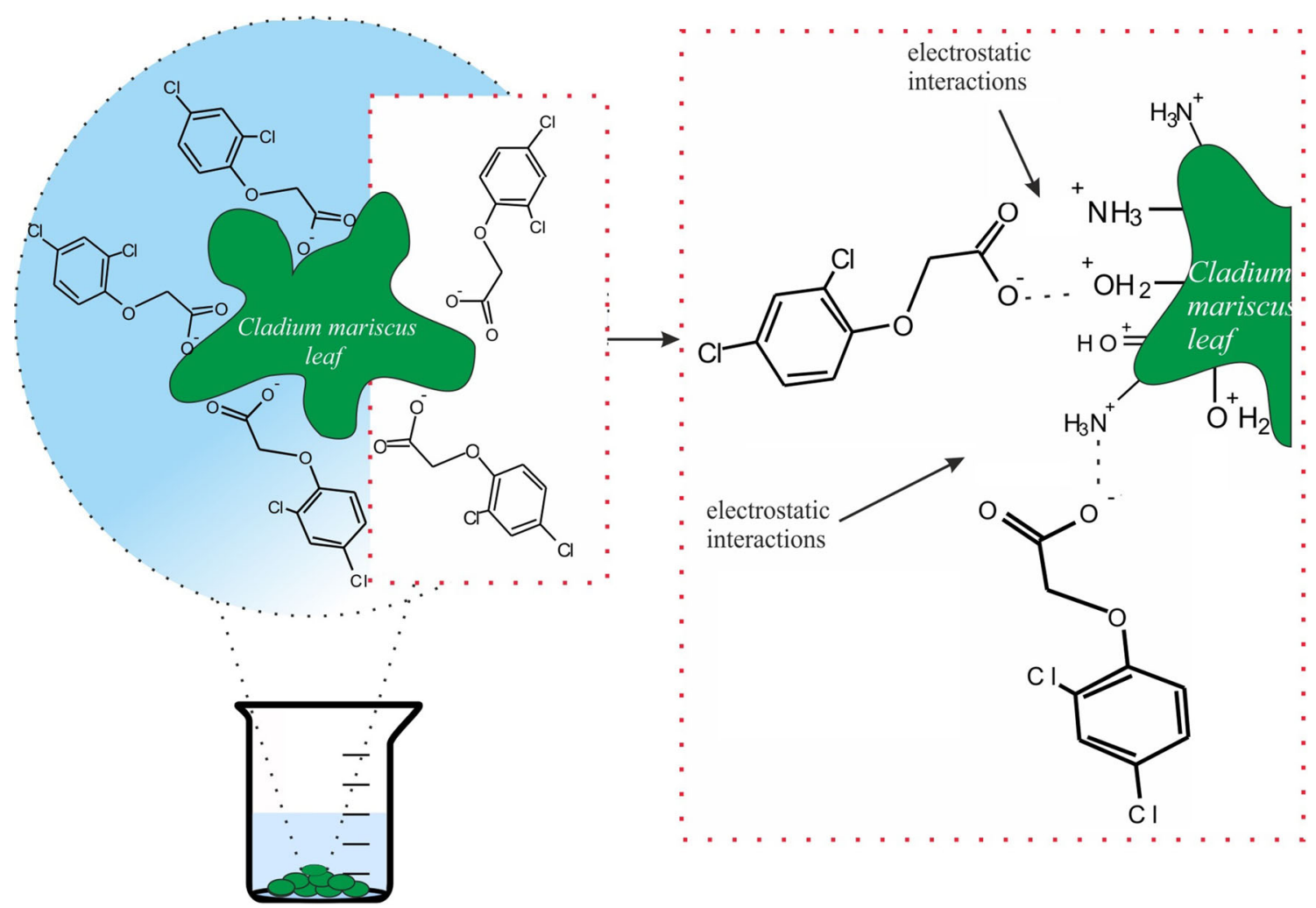

Fig. 6 Proposed mechanism of adsorption of 2,4-D on the surface of Cladium mariscus 


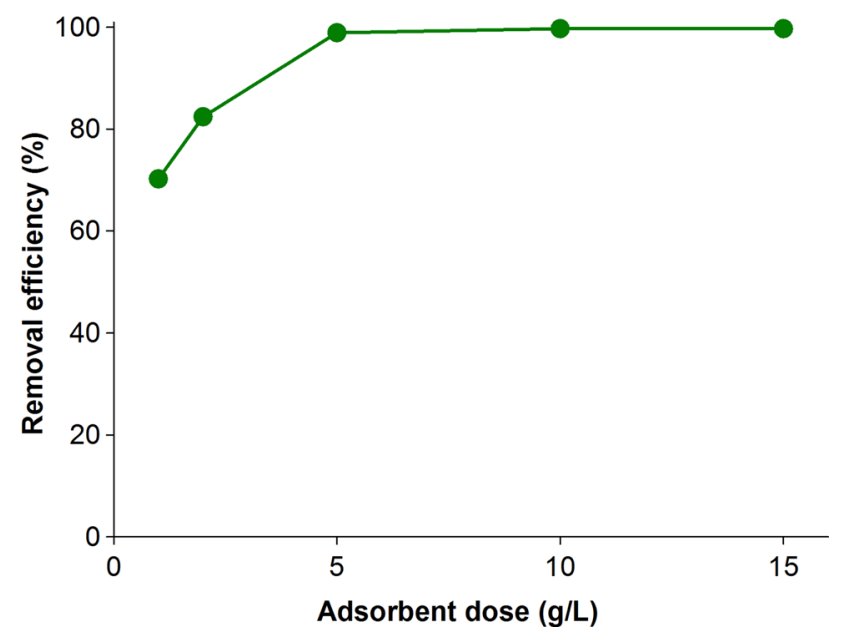

Fig. 7 Effect of adsorbent dose on 2,4-D removal by Cladium mariscus (2,4-D concentration $50 \mathrm{mg} / \mathrm{L}, \mathrm{pH} 4.5$, time $60 \mathrm{~min}$, adsorbent dose $0.5 \mathrm{~g}$, temperature $25^{\circ} \mathrm{C}$ )

The negative values of $\Delta H^{\circ}$ indicate that the process is exothermic, while the negative values of $\Delta G^{\circ}$ for the process of adsorption of 2,4-D at all three temperatures show the process to be spontaneous. With increasing temperature, the degree of spontaneity of the process decreases, in accordance with the exothermic nature of the process. Furthermore, the values of change of entropy $\left(\Delta S^{\circ}\right)$ describe the randomness in the interactions between adsorbent and adsorbate. Nonetheless, the negative values of $\Delta S^{\circ}$ point to complex interactions between adsorbent and adsorbate.

Researchers investigating different materials have obtained similar results. Salman et al. (2011a, b) and Jung et al. (2013) determined thermodynamic parameters in order to better understand the mechanism of adsorption of 2,4-D on the surface of activated carbon obtained from oil palm leaves, activated carbon from banana stalks (Salman et al. 2011a, b), and a mesoporous metal-organic framework material (Jung et al. 2013). Their results also confirm the spontaneous and exothermic nature of the adsorption of 2,4-D. It should be noted, however, that both research teams obtained positive values for the change of entropy, which may be due to the greater randomness of the interactions on the phase contact surface and the greater quantity of adsorbed water relative to 2,4-D. These results suggest that $C$. mariscus is a more effective adsorbent of this herbicide from aqueous systems.
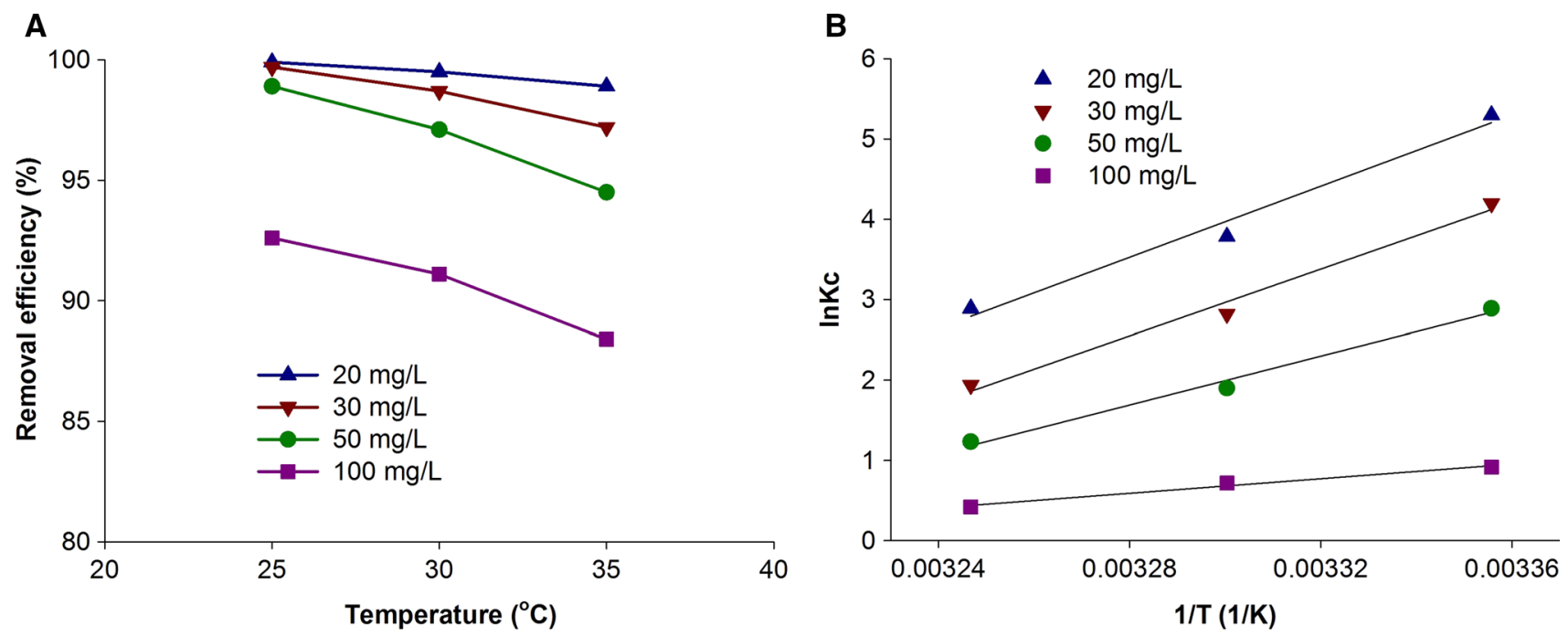

Fig. 8 Effect of temperature on 2,4-D removal by Cladium mariscus (2,4-D concentration $50 \mathrm{mg} / \mathrm{L}$, pH 4.5, time 60 min) (a) and log $K_{c}$ versus $1 / T$ (b)

Table 6 Thermodynamic parameters of the adsorption of 2,4-D onto Cladium mariscus

\begin{tabular}{lccccc}
\hline Concentration of 2,4-D (mg/L) & $\Delta H^{\circ}(\mathrm{kJ} / \mathrm{mol})$ & $\Delta S^{\circ}(\mathrm{J} / \mathrm{mol} \mathrm{K})$ & \multicolumn{4}{l}{$\Delta G^{\circ}(\mathrm{kJ} / \mathrm{mol})$} \\
\cline { 3 - 6 } & & & $25{ }^{\circ} \mathrm{C}$ & $30{ }^{\circ} \mathrm{C}$ & $35{ }^{\circ} \mathrm{C}$ \\
\hline 20 & -184.08 & -574.73 & -12.81 & -9.93 & -7.06 \\
30 & -172.66 & -545.39 & -10.13 & -7.40 & -4.68 \\
50 & -126.41 & -400.57 & -7.04 & -5.04 & -3.03 \\
100 & -37.80 & -119.09 & -2.31 & -1.72 & -1.12 \\
\hline
\end{tabular}




\subsection{Isothermal studies}

Isotherms for the adsorption of 2,4-D by $C$. mariscus were determined using the models of Freundlich and Langmuir. The diagrams in Fig. 9 show fits of the experimental data to those models based on graphs of $C_{e} / q_{e}$ against $C_{e}$ and $\log \left(q_{e}\right)$ against $\log \left(C_{e}\right)$. These enabled calculation of the parameters of the isotherms, which are given in Table 7.

The Freundlich isotherm (1906) is described by the following linear Eq. (6):

$\log q_{e}=\log K_{F}+\log C_{e}^{\frac{1}{n}}$

where $K_{F}(\mathrm{mg} / \mathrm{g})$ is a measure of adsorption capacity, and $\frac{1}{n}$ denotes the intensity of adsorption.

The Langmuir isotherm equation has the following linear form (1918) (7):

$\frac{C_{e}}{q_{e}}=\frac{1}{b q_{m}}+\frac{C_{e}}{q_{m}}$

where: $C_{e}(\mathrm{mg} / \mathrm{L})$ is the equilibrium concentration of ions in solution; $q_{e}(\mathrm{~mol} / \mathrm{g})$ is the quantity of adsorbate adsorbed at equilibrium; $q_{m}(\mathrm{mg} / \mathrm{g})$ is the maximum sorptive capacity; $b(-)$ is Langmuir's constant.

The linear correlation coefficients $\left(R^{2}\right)$ for the two models have similar values $(0.982-0.988)$, which indicates the complexity of the process mechanism and the heterogeneity of the adsorbent surface. The experimental data are slightly better described by Langmuir's model. Assuming the formation of a monolayer, it is possible to determine the adsorption capacity $\left(q_{m}\right)$, which in the case of C. mariscus was found to be $65.58 \mathrm{mg} / \mathrm{g}$. For the model assuming heterogeneity of the surface, however, the value $K_{F}$ was calculated as $8.93 \mathrm{mg} / \mathrm{g}$. Another parameter of the Freundlich model is the constant $n$. For all experiments it was found that $n>1$, which indicates the predominantly physical nature of the adsorption, confirming the previous assumptions concerning the adsorption mechanism.

At the next stage the adsorption capacity of the studied material was compared with that of other adsorbents (see Table 7). C. mariscus demonstrates a significant sorptive capacity, which means that it may be successfully used as an effective low-cost adsorbent of 2,4-dichlorophenoxyacetic acid.

\subsection{FTIR spectroscopy}

FTIR spectra of $C$. mariscus, 2,4-dichlorophenoxyacetic acid (2,4-D), and the product after adsorption (2,4-D concentration $50 \mathrm{mg} / \mathrm{L}$, adsorbent dose $0.5 \mathrm{~g}$, time $60 \mathrm{~min}$, temperature $25^{\circ} \mathrm{C}, \mathrm{pH}=4.5$ ) are presented in Fig. 10 . The most important bands are summarized in Table 8 .

The FTIR spectrum of $C$. mariscus shows the presence of bands characteristic for the groups forming the structure of the adsorbent. FTIR analysis of 2,4-dichlorophenoxyacetic acid reveals peaks at 3072,1482 and $641 \mathrm{~cm}^{-1}$ associated with vibrations of aromatic structures, and signals at 3389, 1733, 1230 and $1095 \mathrm{~cm}^{-1}$ which can be assigned to vibrations of carboxylic groups (Nejati et al. 2013).

Most important is the spectrum of the product after adsorption of 2,4-D by $C$. mariscus. This shows the presence of bands at $3408,3278,2920,2853,1738,1634,1478$, $1315,1236,1092,1057$ and $1055 \mathrm{~cm}^{-1}$, which are characteristic for the structural vibrations of both the sorbent and 2,4-D (Pavlovic et al. 2005). The peaks at 3069 and $642 \mathrm{~cm}^{-1}$ correspond to other vibrations of groups present in the 2,4-dichlorophenoxyacetic acid structure. The presence of all of these signals confirms the successful
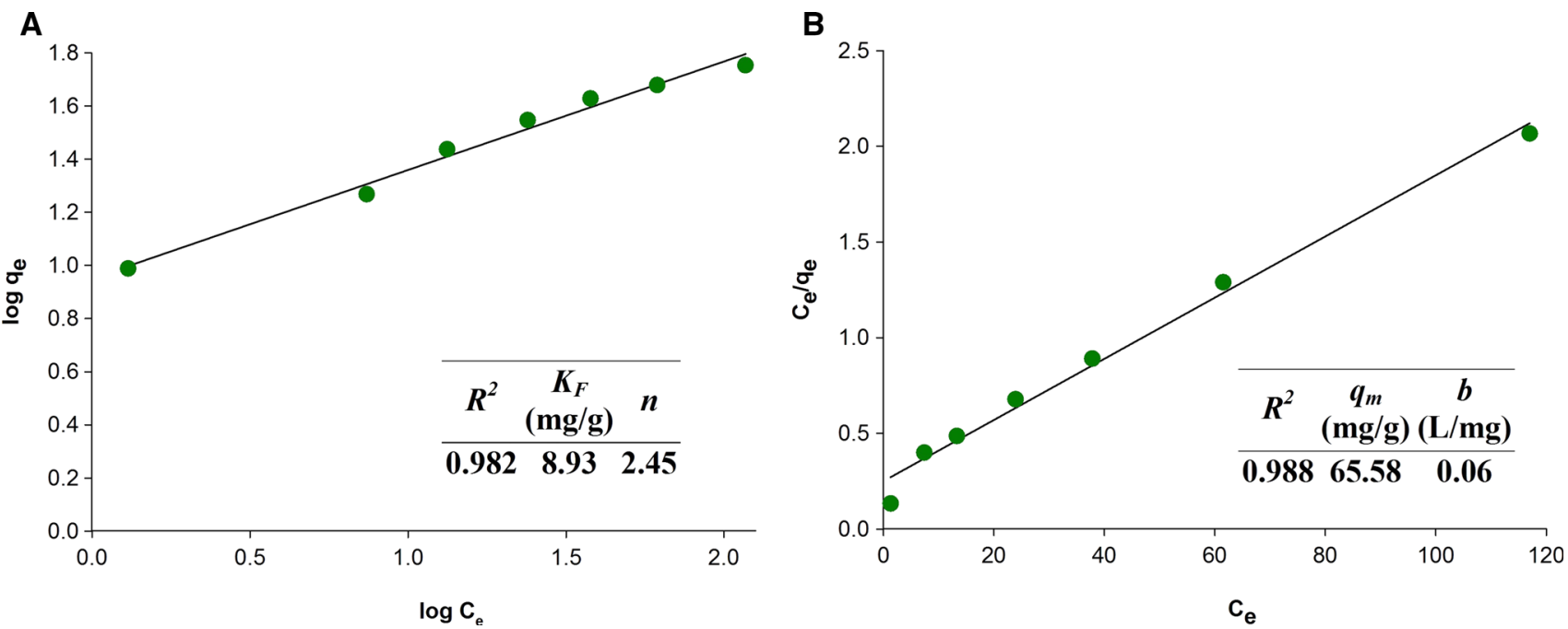

Fig. 9 Linear adsorption isotherms models of Freundlich (a) and Langmuir (b), and isotherm constants for 2,4-D with Cladium mariscus 
Table 7 Comparison of adsorption capacity towards removal of 2,4-D acid by other adsorbents

\begin{tabular}{lll}
\hline Adsorbent type & $q_{m}(\mathrm{mg} / \mathrm{g})$ & Reference \\
\hline Powdered activated carbon & 97.4 & Aksu and Kabasakal (2005) \\
Cladium mariscus & 65.58 & This study \\
Blast furnace sludge & 30.0 & Gupta et al. (2006) \\
Blast furnace dust & 21.0 & Gupta et al. (2006) \\
Modified silica gel & 17.7 & Koner et al. (2013) \\
Surface modified activated carbon (AC F400AN) & $11.76-16.25$ & Son Tran et al. (2015) \\
Chitosan & 11.0 & Harmoudi (2014) \\
Commercial activated carbon (AC F400) & $8.13-10.48$ & Son Tran et al. (2015) \\
Chitin & 6.0 & Harmoudi (2014)
\end{tabular}

The slight shifts in the maximal wavenumbers of the

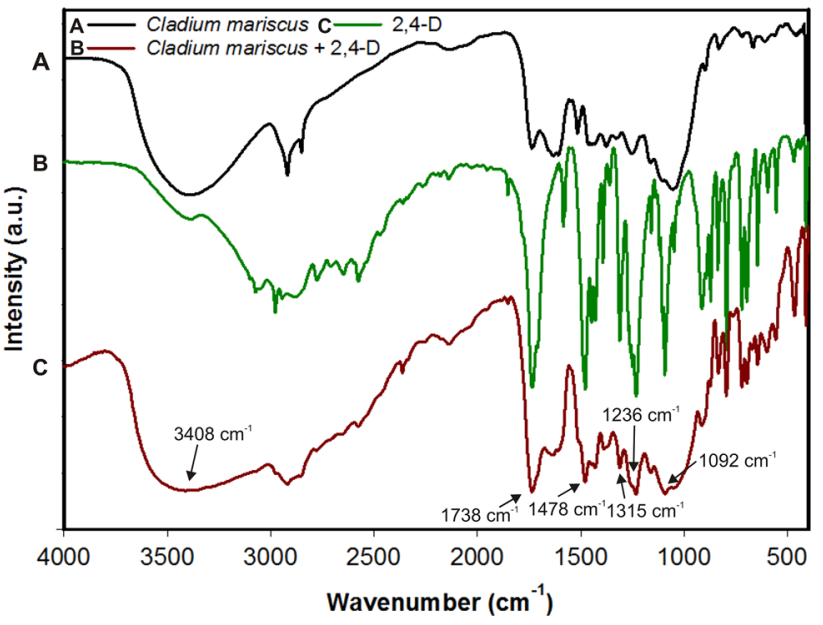
peaks in the spectrum of the product after adsorption compared with the spectra of C. mariscus and 2,4dichlorophenoxyacetic acid might suggest that the interactions between adsorbent and adsorbate are based on hydrogen bonds Hajdú et al. 2012.

\section{Conclusions}

In this study, for the first time in the scientific literature, research has been carried out on the process of adsorption of 2,4-dichlorophenoxyacetic acid (2,4-D) from aqueous systems using saw-sedge $C$. mariscus, collected in the east part of Lublin region. C. mariscus consists chiefly of carbon $(48 \%)$ and hydrogen $(7 \%)$. The presence of these elements can be explained by the occurrence of surface functional groups on the surface of the material, as was confirmed by FTIR analysis. The plant material has a relatively small BET surface area $\left(A_{B E T}=0.6 \mathrm{~m}^{2} / \mathrm{g}\right)$ and a total pore volume of $V_{p}=0.001 \mathrm{~cm}^{3} / \mathrm{g}$. Hence the sorptive capacity of this material, considering the low surface area, is conditioned by the presence of functional groups on its surface. The effectiveness of removal of 2,4-D from
Table 8 Maximal vibrational wavenumbers $\left(\mathrm{cm}^{-1}\right)$ of Cladium mariscus, 2,4dichlorophenoxyacetic acid, and products after adsorption

\begin{tabular}{llll}
\hline Vibrational assignment & Cladium mariscus & $2,4-\mathrm{D}$ acid & Cladium mariscus + 2,4-D acid \\
\hline O-H stretching & 3414 & 3389 & 3408 \\
$\mathrm{~N}-\mathrm{H}$ stretching & 3267 & - & 3278 \\
$\mathrm{C}_{\mathrm{Ar}}-\mathrm{H}$ stretching & - & 3072 & 3069 \\
$\mathrm{C}-\mathrm{H}$ stretching & 2916,2846 & 2980 & 2920,2853 \\
$\mathrm{C}=\mathrm{O}$ stretching & 1734 & 1733 & 1738 \\
$\mathrm{~N}-\mathrm{H}$ stretching & 1625 & - & 1634 \\
$\mathrm{C}_{\mathrm{Ar}}=\mathrm{C}_{\mathrm{Ar}}$ & 1465 & 1482 & 1478 \\
$\mathrm{C}-\mathrm{O}-\mathrm{C}$ asymetric & 1322 & 1307 & 1315 \\
$\mathrm{C}-\mathrm{OH}$ deformational & 1247 & 1230 & 1236 \\
$\mathrm{C}-\mathrm{O}$ stretching & 1054 & 1095 & 1092,1055 \\
$\mathrm{C}-\mathrm{O}-\mathrm{C}$ symetric & 1054 & 1058 & 1057 \\
$\mathrm{C}_{\mathrm{Ar}}-\mathrm{Cl}$ stretching & - & 641 & 642
\end{tabular}


aqueous systems using $C$. mariscus is dependent on four basic process parameters, namely the contact time between adsorbate and adsorbent, the $\mathrm{pH}$ of the system, the mass of sorbent used, and the temperature. The results show that in the initial stage the process of adsorption proceeds extremely rapidly. Depending on the solution concentration, equilibrium was attained after different contact times of adsorbate with adsorbent (30 min for concentrations of 20 and $30 \mathrm{mg} / \mathrm{L}, 60 \mathrm{~min}$ for 50 and $100 \mathrm{mg} / \mathrm{L}$ ). It was also found that the $\mathrm{pH}$ has a significant influence on the effectiveness of removal of 2,4-D. Maximum adsorption was attained for a solution at $\mathrm{pH}=3$. Further increase in the alkalinity of the tested systems led to a decrease in the effectiveness of adsorption. It was also shown that the effectiveness of removal of 2,4-D increases as the mass of material used increases. This is due to the greater contact surface between adsorbate and adsorbent. It was also shown that with an increase in the temperature at which the adsorption process took place, the effectiveness of removal of 2,4-D decreased slightly. The inverse proportionality of the effectiveness of adsorption of 2,4-D with respect to temperature implies that the process is exothermic.

An investigation was made of the kinetic of adsorption of 2,4-D by $C$. mariscus. The experimental data corresponded to a pseudo-second-order kinetic model of type 1 . The adsorption rate constant $\left(k^{2}\right)$ decreased with increasing concentration of 2,4-D in model solution.

Detailed thermodynamic analysis showed values of $\Delta H^{\circ}$ to be negative, which confirms the exothermic nature of the process. Meanwhile, negative values of $\Delta G^{\circ}$ for the process of adsorption of 2,4-D at all analyzed temperatures indicate that the process is spontaneous.

Acknowledgments This article was partially supported within the project "Engineer of the Future. Improving the didactic potential of the Poznan University of Technology"-POKL.04.03.00-00-259/12, implemented within the Human Capital Operational Programme, cofinanced by the European Union within the European Social Fund. The work was also financed within the National Centre of Science Poland funds according to Decision No. DEC-2013/09/N/ST8/00319.

Open Access This article is distributed under the terms of the Creative Commons Attribution 4.0 International License (http://crea tivecommons.org/licenses/by/4.0/), which permits unrestricted use, distribution, and reproduction in any medium, provided you give appropriate credit to the original author(s) and the source, provide a link to the Creative Commons license, and indicate if changes were made.

\section{References}

Aksu, Z., Kabasakal, E.: Batch adsorption characteristics of 2,4dichlorophenoxy-acetic acid (2,4-D) from aqueous solution on powdered activated carbon. J. Environ. Sci. Health Part B 40, $545-570$ (2005)
Aksu, Z., Kabasakal, E.: Batch adsorption of 2,4-dichlorophenoxyacetic acid $(2,4-\mathrm{D})$ from aqueous solution by granular activated carbon. Sep. Purif. Technol. 35, 223-240 (2004)

Aktar, W., Sengupta, D., Chowdhury, A.: Impact of pesticides use in agriculture: their benefits and hazards. Interdisc. Toxicol. 2, $1-12(2009)$

Akunwa, N.K., Muhammad, M.N., Akunna, J.C.: Treatment of metalcontaminated wastewater: a comparison of low-cost biosorbents. J. Environ. Manage. 146, 517-523 (2014)

Ali, I., Asim, M., Khan, T.A.: Low cost adsorbents for the removal of organic pollutants from wastewater. J. Environ. Manage. 113, 170-183 (2012)

Bartczak, P., Norman, M., Klapiszewski, Ł., Karwańska, N., Kawalec, M., Baczyńska, M., Wysokowski, M., Zdarta, J., Ciesielczyk, F., Jesionowski, T.: Removal of nickel(II) and lead(II) ions from aqueous solution using peat as a low-cost adsorbent: a kinetic and equilibrium study. Arab. J. Chem. (2015). doi:10.1016/j.arabjc.2015.07.018

Bradberry, S.M., Proudfoot, A.T., Vale, J.A.: Poisoning due to chlorophenoxy herbicides. Toxicol. Rev. 23, 65-73 (2004)

Cavani, F., Trifiro, F., Vaccari, A.: Hydrotalcite-type anionic clays: preparation, properties and applications. Catal. Today 11, 173-301 (1991)

Chaparadza, A., Hossenlopp, J.M.: Removal of 2,4-dichlorophenoxyacetic acid by calcined $\mathrm{Zn}-\mathrm{Al}-\mathrm{Zr}$ layered double hydroxide. J. Colloid Interface Sci. 363, 92-97 (2011)

Derylo-Marczewska, A., Blachnio, M., Marczewski, A.W., Swiatkowski, A., Tarasiuk, B.: Adsorption of selected herbicides from aqueous solution on activated carbon. J. Therm. Anal. Calorim. 101, 785-794 (2010)

Foroughi-Dahr, M., Abolghaseml, H., Esmaili, M., Shojamoradi, A., Fatoorehchi, H.: Adsorption characteristics of congo red from aqueous solution onto tea waste. Chem. Eng. Commun. 202, 181-193 (2015)

Freundlich, H.M.F.: Over the adsorption in solution. J. Phys. Chem. 57, 385-470 (1906)

Garabant, D.H., Philbert, M.A.: Review of 2,4-dichlorophenoxyacetic acid (2,4-D) epidemiology and toxicology. Crit. Rev. Toxicol. 32, 233-257 (2002)

Goscianska, J., Marciniak, M., Pietrzak, R.: Mesoporous carbons modified with lanthanum(III) chloride for methyl orange adsorption. Chem. Eng. J. 247, 258-264 (2014)

Goscianska, J., Olejnik, A., Pietrzak, R.: Comparison of ordered mesoporous materials sorption properties towards amino acids. Adsorption 19, 581-588 (2013)

Gupta, V.K., Ali, I., Saini, V.K.: Adsorption of 2,4-D and carbofuran pesticides using fertilizer and steel industry wastes. J. Colloid Interface Sci. 299, 556-563 (2006)

Hajdú, A., Szekeres, M., Tóth, I.Y., Bauer, R.A., Mihály, J., Zupkó, I., Tombácza, E.: Enhanced stability of polyacrylate-coated magnetite nanoparticles in biorelevant media. Colloid Surf. B 94, 242-249 (2012)

Hameed, B.H., Salman, J.M., Ahmad, A.L.: Adsorption isotherm and kinetic modeling of 2,4-D pesticide on activated carbon derived from date stones. J. Hazard. Mater. 163, 121-126 (2009)

Harmoudi, H.El., Gaini, L.El., Daoudi, E., Rhazi, M., Boughaleb, Y., Mhammedi, M.A.El., Migalska-Zalas, A., Bakasse, M.: Removal of 2,4-D from aqueous solution by adsorption processing using two biopolymers: chitin and chitosan and their optical properties. Opt. Mater. 36, 1471-1477 (2014)

Ho, Y.S., McKay, G.: Pseudo-second order model for sorption processes. Process Biochem. 34, 451-465 (1999)

Jung, B.K., Hasan, Z., Jhung, S.H.: Adsorptive removal of 2,4dichlorophenoxyacetic acid (2,4-D) from water with a metalorganic framework. Chem. Eng. J. 234, 99-105 (2013) 
Kaminski, W., Kusmierek, K., Swiatkowski, A.: Sorption equilibrium prediction of competitive adsorption of herbicides 2,4-D and MCPA from aqueous solution on activated carbon using ANN. Adsorption 20, 899-904 (2014)

Koner, S., Pal, A., Adak, A.: Adsorption of 2,4-D herbicide from water environment on modified silica gel factory waste. Water Environ. Res. 85, 2147-2156 (2013)

Lagergren, S.: About the theory of so-called adsorption of soluble substances. Kungliga Svenska Vetensk. Handl. 24, 1-39 (1898)

Langmuir, I.: The adsorption of gases on plane surfaces of glass, mica and platinum. J. Am. Chem. Soc. 40, 1361-1403 (1918)

Mohammad, S.G., Ahmed, S.M., Badawi, A.F.M.: A comparative adsorption study with different agricultural waste adsorbents for removal of oxamyl pesticide. Desalin. Water Treat. 55, 2109-2120 (2015)

Nam, S.-W., Coi, D.-J., Kim, S.-K., Her, N., Zoh, K.-D.: Adsorption characteristic of selected hydrophilic and hydrophobic micropolluants in water using activated carbon. J. Hazard. Mater. 270, 144-152 (2014)

Nejati, K., Davary, S., Saati, M.: Study of 2,4-dichlorophenoxyacetic acid $(2,4-\mathrm{D})$ removal by $\mathrm{Cu}-\mathrm{Fe}-\mathrm{layered}$ double hydroxide from aqueous solution. Appl. Surf. Sci. 280, 67-73 (2013)

Nethaji, S., Sivasamy, A.: Removal of herbicide (2,4-dichlorophenoxyacetic acid) in aqueous solution using magnetite activated carbon derived from waste biomass. Int. J. Appl. Eng. Res. 1, 65-70 (2014)

Njoku, V.O., Asif, M., Hameed, B.H.: 2,4-Dichlorophenoxyacetic acid adsorption onto coconut shell-activated carbon: isotherm and kinetic modelling. Desalin. Water Treat. 55, 132-141 (2015)

Ova, D., Ovez, B.: 2,4-Dichlorophenoxyacetic acid removal from aqueous solutions via adsorption in the presence of biological contamination. J. Environ. Chem. Eng. 1, 813-821 (2013)

Pavlovic, I., Barriga, C., Hermosín, M.C., Cornejo, J., Ulibarri, M.A.: Adsorption of acidic pesticides 2,4-D, Clopyralid and Picloram on calcined hydrotalcite. Appl. Clay Sci. 30, 125-133 (2005)

Pirsaheb, M., Dargahi, A., Hazrati, S., Fazlzadehdavil, M.: Removal of diazinon and 2,4-dichlorophenoxy-acetic acid (2,4-D) from aqueous solutions by granular-activated carbon. Desalin. Water Treat. 52, 4350-4355 (2014)

Salman, J.M.: Optimization of preparation conditions for activated carbon from palm oil fronds using response surface methodology on removal of pesticides from aqueous solution. Arab. J. Chem. 7, 101-108 (2014)
Salman, J.M., Al-Saad, K.A.: Adsorption of 2,4-dichlorophenoxyacetic acid onto date seeds activated carbon: equilibrium, kinetic and thermodynamic studies. Int. J. Chem. Sci. 10, 677-690 (2012)

Salman, J.M., Njoku, V.O., Hameed, B.H.: Adsorption of pesticides from aqueous solution onto banana stalk activated carbon. Chem. Eng. J. 174, 41-48 (2011a)

Salman, J.M., Njoku, V.O., Hameed, B.H.: Batch and fixed-bed adsorption of 2,4 dichlorophenoxyacetic acid onto oil palm frond activated carbon. Chem. Eng. J. 174, 33-40 (2011b)

Shabeer, T.P.A., Saha, A., Gajbhiye, V.T., Gupta, S., Manjaiah, K.M.: Simultaneous removal of multiple pesticides from water: effect of organically modified clays as coagulant aid and adsorbent in coagulation-flocculation process. Environ. Technol. 35, 2619-2627 (2014)

Son Tran, V., Ngo, H.H., Guo, W., Zhang, J., Liang, S., Ton-That, C., Zhang, X.: Typical low cost biosorbents for adsorptive removal of specific organic pollutants from water. Bioresour. Technol. 182, 353-363 (2015)

Souzaa, F.L., Saézb, C., Lanzaa, M.R.V., Cañizaresb, P., Rodrigo, M.A.: Removal of herbicide 2,4-D using conductive-diamond sono-electrochemical oxidation. Sep. Purif. Technol. 149, 24-30 (2015)

Sultana, J., Syed, J.H., Mahmood, A., Ali, U., Rehman, M.Y.A., Malik, R.N., Li, J., Zhang, G.: Investigation of organochlorine pesticides from the Indus Basi, Pakistan: sources, air-soil exchange fluxes and risk assessment. Sci. Total Environ. 497-498, 113-122 (2014)

Theocharopoulos, M., Georgiadis, T., Dimitrellos, G., Chochliouros, S., Tiniakou, A.: Vegetation types with Cladium mariscus (Cyperaceae) in Greece. Willdenowia 36, 247-256 (2006)

Tomlin, C.D.S.: The pesticide manual. A world compendium. British Crop Production Council, Hampshire (2009)

Yang, X., Wang, F., Meng, L., Zhang, W., Fan, L., Gessen, V., Ritsema, C.J.: Farmer and retailer knowledge and awareness of the risks from pesticide use: a case study in the river catchment, China. Sci. Total Environ. 497, 172-179 (2014)

Zhang, X., Lu, X., Li, S., Zhong, M., Shi, X., Luo, G., Ding, L.: Investigation of 2,4-dichlorophenoxyacetic acid adsorption onto MIEX resin: optimization using response surface methodology. J. Taiwan Inst. Chem. 45, 1835-1841 (2014) 